Aki Siegel*

\title{
Superficial intersubjectivity in ELF university dormitory interactions
}

\author{
https://doi.org/10.1515/jelf-2018-0015
}

Abstract: The current study investigates the phenomena of "superficial intersubjectivity" occurring in English as a lingua franca (ELF) interactions at an international university dormitory in Japan. "Intersubjectivity" (Rommetveit, Ragnar. 1976. On the architecture of intersubjectivity. In Ragnar Rommetveit \& Rolv Mikkel Blakar [eds.], Studies of language, thought, and verbal communication, 93-107. New York: Academic Press) refers to the shared perspective of the social world by the interlocutors. In ELF interactions where shared perspectives cannot be presumed, efforts to achieve intersubjectivity are critical. ELF research has explicated speakers' efforts and cooperativeness to achieve intersubjectivity or avoid misunderstandings during interactions (Kaur, Jagdish. 2011a. "Doing being a language expert”: The case of the ELF speaker. In Alasdair Archibald, Alessia Cogo \& Jennifer Jenkins [eds.], Latest Trends in ELF Research, 53-75. Newcastle upon Tyne: Cambridge Scholars Publishing; Seidlhofer, Barbara. 2001. Closing a conceptual gap: The case for a description of English as a lingua franca. International Journal of Applied Linguistics 11[2]. 133-158). However, few studies have investigated cases where speakers display mutual understanding during a repair sequence even when the understanding is not accurate.

Approximately 37 hours of naturally occurring ELF interactions were collected and analyzed using a standard conversation analysis followed by a post-analytic researcher observation. Detailed analyses of repair sequences regarding a word suggest that in non-institutional ELF interactions the accuracy of intersubjectivity is not always prioritized. Rather, statements made by the speaker positioned as the one with relatively stronger linguistic ability seem to hold influence over the repair sequence, which prompts the interlocutor with relatively weaker ability to agree with inaccurate candidate understandings. The study suggests a connection between the positioning of speakers regarding linguistic knowledge and the construction of intersubjectivity in ELF interactions.

Keywords: English as a lingua franca, intersubjectivity, repair sequence

*Corresponding author: Aki Siegel, Guest Researcher, Stockholm University, SE-106 91, Stockholm, Sweden, E-mail: aki.siegel@gmail.com 
要旨: 本稿は日本における国際的な大学寮で取り交わされた共通語としての 英語（ELF）の相互行為を通してみられた「表面的な共有理解」について探究 する。共有理解、もしくは「間主観性」（Rommetveit 1976）とは話者同士が現 実社会に関して共有する認識のことである。使用言語を含め、共有認識を前 提とできないELF相互行為において共有理解を維持する努力は非常に重要であ る。ELFの先行研究は共有理解を得たり誤解を避けたりする為の話者らによる 協力的な姿勢や様々な手法を明らかにしてきた（例：Kaur (2011a); Seidlhofer (2001)）。しかし、修復連鎖中において話者らが正確な理解が得られていない 場合でも同意を示す事象を分析した研究はほとんどない。

本研究は約37時間の自然発生的会話データに会話分析を施した後、研究 者による観察を用いて分析した。その結果、大学内であっても教室外のELF相 互行為においては共有理解の正確さが常に優先されるとは限らないことがみ えてきた。むしろ、話者間で比較的言語能力の高い位置づけにある話者によ る発言は同意形成過程に強い影響力を持っており、比較的言語能力の低い位 置づけにある話者が不正確な理解に同意を示すことにつながっていた。本研 究結果は話者の言語知識に関する相互行為上の位置づけと共有理解構築の間 に関連があることを示唆している。

キーワード: 共通語としての英語, 間主観性, 共有理解, 修復連鎖

\section{Introduction}

The current study examines the phenomenon of "superficial intersubjectivity" in naturally occurring English as a lingua franca (ELF) interactions at an international university dormitory in Japan. Internationalization of universities in Japan has been a key topic for the Japanese government, especially the Ministry of Education, Culture, Sports, Science and Technology (MEXT). Several universities in Japan have invited large numbers of students from around the world and offer degree programs in English (MEXT 2008, MEXT 2011). Of these, 13 universities were selected by MEXT, and received national recognition in continuing their efforts to develop an international environment and educate future graduates who will contribute to the globalization of Japan (i.e. Global 30 project) (MEXT 2008).

These universities profess to be multilingual and ELF environments where both English and Japanese are used as common languages among the students, teachers, and staff members. Despite interest in these international universities in Japan from ELF researchers (e.g. Jenkins 2013), the actual language use on these campuses, including English, is an area that needs further investigation (with some exceptions such as Taguchi [2011]). In particular, language use outside the second language (L2) English classroom, where there are no pre-determined or standardized norms of the English language, has been rarely documented. 
ELF is used in this paper to refer to English used as contact language between speakers from different linguistic and cultural backgrounds (Archibald et al. 2011). In ELF interactional environments where shared perspectives, including the language being used, cannot be presumed, efforts to achieve intersubjectivity are critical. Intersubjectivity refers to a shared understanding of a topic or social reality achieved through interaction (Rommetveit 1976, Rommetveit 1985). From an interactional perspective, "understanding" is co-constructed in the ongoing interaction (Schegloff 1992). In the interaction, each turn is responsive to the prior turn, and therefore becomes a display of understandings of what has occurred earlier in the talk. In other words, the understandings are displayed en passant through actions such as agreeing, assessing, and responding. Moreover, through their talk and display of (non-)understanding of the prior turns, speakers can identify or reveal problems in understanding, which can then be resolved through the talk. Thus, intersubjectivity is constructed and continuously updated between the interlocutors on a turn-by-turn basis (Heritage 1984). Since these understandings are publicly produced, observers can analyze when and how intersubjectivity is constructed (Heritage 1984).

ELF studies have investigated various interactional practices utilized by interlocutors in order to achieve or secure mutual understanding. These include practices such as the use of self-repetition (Björkman 2011; Kaur 2009, Kaur 2010; Lichtkoppler 2007), repetition of the prior speaker (Björkman 2011; House 2003; Lichtkoppler 2007), self-initiated self-repair (Kaur 2011b; Mauranen 2006; Cogo 2010), request for confirmation or clarification (Cogo and Dewey 2012; Kaur 2010; Mauranen 2006), initiation of comprehension checks (Kaur 2009; Mauranen 2006), paraphrasing (Kaur 2009, Kaur 2010; Lichtkoppler 2007), and code-switching (Klimpfinger 2007).

ELF research has repeatedly shown the efforts made by interlocutors to avoid misunderstandings and secure intersubjectivity, as well as the general cooperativeness and supportiveness of speakers in achieving mutual understanding (Firth 1996; Kaur 2011a; Seidlhofer 2001), even if the language use may be sometimes direct (Konakahara 2015). Seidlhofer states, "ELF interactions often are consensusoriented, cooperative and mutually supportive” (Seidlhofer 2001: 143), where participants in the talk use various affordances to facilitate the progress of communication. In non-repair sequence contexts, however, studies have found interactants in ELF interactions being uncooperative or even confrontational (Bjørge 2012; House 1999; Jenks 2012; Knapp 2002; Konakahara 2017; Wolfartsberger 2011).

When the interlocutors display agreement or understanding, intersubjectivity is assumed (Schutz 1967), and the speakers will resume the main conversation. In general, a claim of recognition or understanding is said to be sufficient for the participants to assume that intersubjectivity has been reached (Heritage 
2007), and participants are thus "released from the task of explicitly confirming and reconfirming their understandings of one another's actions" (Heritage 1984: 259). However, interlocutors may display understanding in repair sequences even when they do not have an "accurate" understanding. This phenomenon, which I term "superficial intersubjectivity," is different from what has been reported in previous studies regarding achieving intersubjectivity in ELF interactions. The current study investigates this phenomenon of superficial intersubjectivity in naturally occurring interactions taking place at an international university dormitory in an attempt to understand the interactional patterns and the reasons why it may occur in ELF interactions.

\section{Repair sequences}

In order to co-construct intersubjectivity between individuals, repair sequences become a crucial mechanism used to restore and achieve mutual understanding. In the field of conversation analysis (CA), "repair" can generally be defined as a modification mechanism of a prior speech production (Schegloff et al. 1977). It is "the set of practices whereby a co-interactant interrupts the ongoing course of action to attend to possible trouble in speaking, hearing or understanding the talk" (Kitzinger 2013: 229). Repairs can be initiated by the speaker or the hearer, and completed by either one as well.

Various studies have been conducted on co-construction of intersubjectivity through repair sequences in ELF interactions. These studies have found that in ELF interactions participants are cautious in achieving accurate understanding and are cooperative during the repair sequences, especially in academic (Kaur 2010, Kaur 2009; Mauranen 2006) or occupational interactions (Firth 2009, Firth 1996; Kuroshima 2010). For instance, Firth (1996, Firth 2009) found that participants in ELF business talk do not bother with "non-standard" English use, such as grammar, phraseological, phonological, prosodic infelicities, that are inconsequential or nonfatal. The turns that follow these non-standard language uses do not demonstrate any non-understandings or misunderstandings by the hearer either. For critical information, however, such as the spelling of names, the condition of the product, or quantity of the shipment, the hearer would make sure to clarify it and confirm its accuracy through multiple turns (Firth 1996). Similar findings are reported in other occupational situations such as ELF service encounters at restaurants (Kuroshima 2010). In her data, the restaurant staff was constantly repeating the order that the customer has said in order to secure an accurate understanding of the order.

The interactional phenomenon to secure an accurate mutual understanding remains consistent for academic contexts as well. Studies have found students 
utilizing repair sequences in securing intersubjectivity (Kaur 2010) or pre-empting misunderstandings through additional turns in talk (Cogo and Dewey 2006; Kaur 2009; Mauranen 2006). Others have found in academic learning, situations where L2 users would support each other through repair sequences to reach mutual understandings (Kaur 2011a). A handful of studies that investigated ELF interactions in international university dormitories have also demonstrated the participants' cooperativeness and collaborative efforts in achieving accurate mutual understandings through repair sequences (Matsumoto 2011; Meierkord 2013).

Among the many types of repair sequences, the current study focuses on repair sequences limited to a single word, including a single word repeated multiple times in succession, such as in "chop chop." The study analyzes sequences in which participants initiate a repair because they are having difficulty in (a) understanding a word from the prior speaker's turn or (b) locating the appropriate linguistic item to convey the meaning that the interlocutor would understand. In other words, these can be self-initiated or other-initiated repair sequences concerning a specific word. Because these repair sequences are performed publicly and jointly with the interlocutor, CA analysts argue that they have "significant interactional consequences" (Hayashi 2003: 114). In these single-word repair sequences, one interlocutor displays "trouble" (Schegloff et al. 1977) understanding or producing a word. The main conversation is then usually put on hold, and the participation framework of the conversation shifts to solving the trouble (i.e. side sequence [Jefferson 1972]). In general, the main conversation is interrupted until the interlocutors display a mutual understanding. Once the participants are satisfied that a common understanding has been reached, they return to the main topic of conversation.

Overlapping with research on repair sequences during ELF interactions, research on repair sequences regarding words in ELF interactions have also reported the various affordances utilized by the speakers in resolving the trouble and achieving intersubjectivity. Among them are, soliciting the help of the relative language expert (Hosoda 2006; Kurhila 2006), simplifying the expression (Bolden 2012), using gestures (Seo and Koshik 2010), and using an additional shared language (Funayama 2002; Greer 2008, Greer 2013; Mori and Hasegawa 2009). These studies have shown that the interlocutors will collaborate, sometimes at length, in order to reach an accurate mutual understanding.

Moreover, studies have demonstrated that the linguistic expertise of the speakers is exposed during repair sequences regarding words (e.g. Greer 2008; Hosoda 2006), especially when the interaction takes place between first language (L1) and L2 speakers. For instance, in his study of multilingual focus groups, Greer (2008) found participants code-switching during their talk and translating words specifically for certain members even when the hearer did not 
initiate repair and provided a receipt token (e.g. "mm”). Greer states, "often an expert speaker does not interpret a receipt token from a novice speaker as an uptake or a display of comprehension" (Greer 2008: 122). His study demonstrates that speakers monitor others' language proficiencies and accommodate certain speakers during conversations in achieving an accurate intersubjectivity. At the same time, by offering a translation, the speaker "casts the recipient in the category of novice (or 'non-native')" (Greer 2008: 99), and makes their own category as an expert relevant.

These studies on repair sequences consisting of words have displayed interactions where the interlocutors agree on the same word or its meaning by the end of the sequence. However, the data from the present study, collected at an international university dormitory, has demonstrated otherwise, and there are cases in which inconsistencies in the interlocutors' understandings seem to exist. While ELF users invest the time and effort in the process of securing intersubjectivity, the participants may agree upon inaccurate information or develop different understandings. Such inaccurate mutual understandings may result in critical consequences for some speakers. The current study explores how these incongruences occur and discusses possible reasons for the phenomena.

\section{The study}

\subsection{Data}

The corpus used for this paper comes from ELF interactions collected at an international university dormitory in Japan. At this university, approximately half of the students are non-Japanese, either L1 speakers of English or students with adequate English skills to study at university in English whose Japanese ability is usually very limited at the beginning of the academic year. The other half are domestic Japanese students who all have at least six years of formal English education at the time of entering. Therefore, English was often used as the lingua franca between the Japanese and non-Japanese students, especially during the first few semesters after matriculation.

In the on-campus university dormitory, there were approximately 3,000 residents, mostly first-year students, at the time of data collection. Approximately half of the residents were Japanese and the other half were non-Japanese students from approximately 90 countries around the world. The majority of the students in the dormitory, however, were from the Asia Pacific region, such as China, Korea, India, Thailand, and Vietnam. 
Approximately 37 hours' worth of video conversations were collected between four Japanese students (i.e. core participants) and their conversation partners. The partners of the core participants were 32 different students from 10 countries. The non-Japanese partners represent countries including Botswana, Canada, China, Korea, Indonesia, Romania, Thailand, United States, Uzbekistan, and Vietnam, based on their registration status at the university. However, some participants had experience living in more than one country for an extended period of time or had parents of different nationalities, and thus represent more than one country or culture. All participants' names used in this paper are pseudonyms.

Video recordings were made by the participants at the dormitory, and the researcher was never present during recordings. The instructions given by the researcher were limited to the positioning of the camera to have all participants visible on the camera screen. The camera was usually set on a desk, and the participants would sit on the bed or the floor while they talked. The conversations were intentionally conducted and recorded, but conversation topics were chosen by the participants and the content was spontaneous. The recordings were transcribed using conversation analysis (CA) conventions (Jefferson 2004). Japanese words have been transcribed in italics with a translation underneath. Transcription conventions are displayed in the appendix.

The analysis was done using a two-stage process, starting with a standard CA (Sacks et al. 1974) followed by a post-analytic researcher observation. CA was selected as the main method of analysis due to its ability to "identify ways in which participants themselves orient to, display, and make sense of one another's cognitive states (among other things)" (Drew 1995: 79). CA is not able to elucidate the actual cognitive state of individuals, nor understand the intentions of why one used a certain language at a certain point. What CA can do is portray the ways in which the interlocutors are making sense of each other's utterances and the process of achieving intersubjectivity or socially distributed cognition (Seedhouse and Walsh 2010). Through utterances, participants display their own cognitive states and at the same time display their understanding of the interlocutor's utterances. In other words, CA takes an emic perspective where the analytical claim is grounded in the participants' visible orientations (Kasper and Wagner 2014).

The outcomes of the emic analysis of the data were then compared to an etic analysis (i.e. the researcher perspective) of the sequence. This second stage of analysis enabled the researcher to demonstrate possible gaps in participants' intersubjectivity. The traditional line of CA research adheres to applying an emic perspective to data. However, recent research, such as with feminist studies and cross-cultural cross-linguistic investigations, have explored the possibility of utilizing pre- and post-analyses in seeking the connections of CA findings to theories and political agendas (e.g. Kitzinger 2008), or comparison of sequential structures 
across different languages (e.g. Fox Hayashi and Jasperson 1996). The analytical method adopted for the current study is similar to these studies in such a way that it utilizes both emic and etic analyses in order to understand the social phenomenon in arguably a holistic way.

\subsection{Analysis}

Initially, all instances of repair sequences regarding a word were identified from the data and examined. From the data, three cases were identified which were different from other repair sequences regarding a word, and the accuracy of the mutual understanding was questionable during the interaction. This section will analyze these three cases along with one case where a potential superficial intersubjectivity was avoided.

The first example is from an interaction between Hang, from Vietnam, and Ami, from Japan, talking about their cultural foods. After Ami initiates a repair, Hang provides an inaccurate translation in order to self-repair. Ami then accepts this inaccurate translation with no hesitation, co-constructing superficial intersubjectivity.

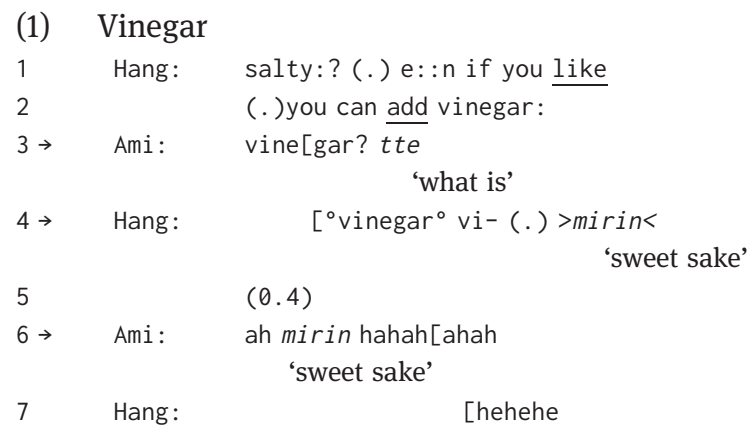

In line 3, Ami displays trouble understanding the word "vinegar" by repeating it with a rising intonation and adding "tte", which can be understood as the reduced form of a question tte nani ('what is it?') in Japanese. Immediately, Hang follows up on this by repeating the word (line 4), which could be understood as Hang seeing the repair initiation by Ami as a possible hearing problem. However, when there is no immediate uptake from Ami, Hang then provides a translation in Japanese, "mirin" (line 4), which is a sweet sake or a sweet wine used for cooking. After a slight pause, Ami displays acceptance of this candidate understanding and understanding by saying "ah" and repeating "mirin", which is then followed by laughter (line 5 and 6 ). This laughter could be interpreted as 
a display of embarrassment due to the simple answer (Glenn 2003). Hang then joins the laughter and the conversation returns to the main topic.

Hang's action in line 4 of providing a translation in Ami's L1 rather than providing an explanation of the object in English suggests Hang's understanding of Ami's turn in line 3 as a display of non-knowing of the English word "vinegar". This translation-providing action by Hang is similar to what Greer (2008) found in his study where a speaker would code-switch to the hearer's L1 in order to secure their understanding. As a result, the speaker presents their perception of the hearer as a novice user of the language. This suggests Hang's perception of Ami as a novice and Ami's English language ability as being possibly limited. At the same time, Ami accepting the translation, along with the embarrassed laughter, could be seen as signs of alignment to the novice-positioning.

The sequential pattern of this repair sequence is a common pattern found in the corpus, in which one participant would display trouble of a single word through the use of a repetition or explicit question, and initiate a repair. In general, the speaker of the trouble source will repair through the use of explanations, translations, or gestures to achieve intersubjectivity (e.g. Bolden 2012; Funayama 2002; Seo and Koshik 2010). From an emic participant-oriented perspective, one can interpret that the two participants have reached a mutual understanding.

However, conducting a post-CA researcher observation, the translation that Hang has provided (mirin) is not an accurate translation of the word vinegar (su in Japanese). Therefore, despite the repair sequence and both participants displaying agreement, the two cannot be said to have reached an "accurate" mutual understanding. This gap identified in the participants' understanding through a comparison between an emic and etic analysis is an example of what I term, "superficial intersubjectivity."

The following two examples also demonstrate interactions where the participants do not seem to prioritize accurate mutual understandings. Excerpt (2) is an example from a recording between Maya and Kei. Maya is from Japan and Kei is from Korea. The excerpt begins where Maya is attempting to explain about the Japanese 'cute culture' (kawaii culture), a concept that refers to a cute and sweet fashion style and lifestyle that can be associated with females wearing lace and pink-colored clothes (Borggreen 2013). Maya uses an onomatopoeia "kira kira kira", to describe the aura that surrounds the people of this cute culture, which is then repaired by Kei.

(2) Bling bling

$\begin{array}{lll}1 & \text { Maya: } & \text { the woman. }(0.4){ }^{\circ} \text { its }^{\circ}(0.4) \\ 2 & & \uparrow c o l o r \text { of }(0.3) \text { pink? } \\ 3 & & (1.0) \\ 4 & \text { Maya: } & \frac{0}{0}: r \\ 5 & & (1.2)\end{array}$




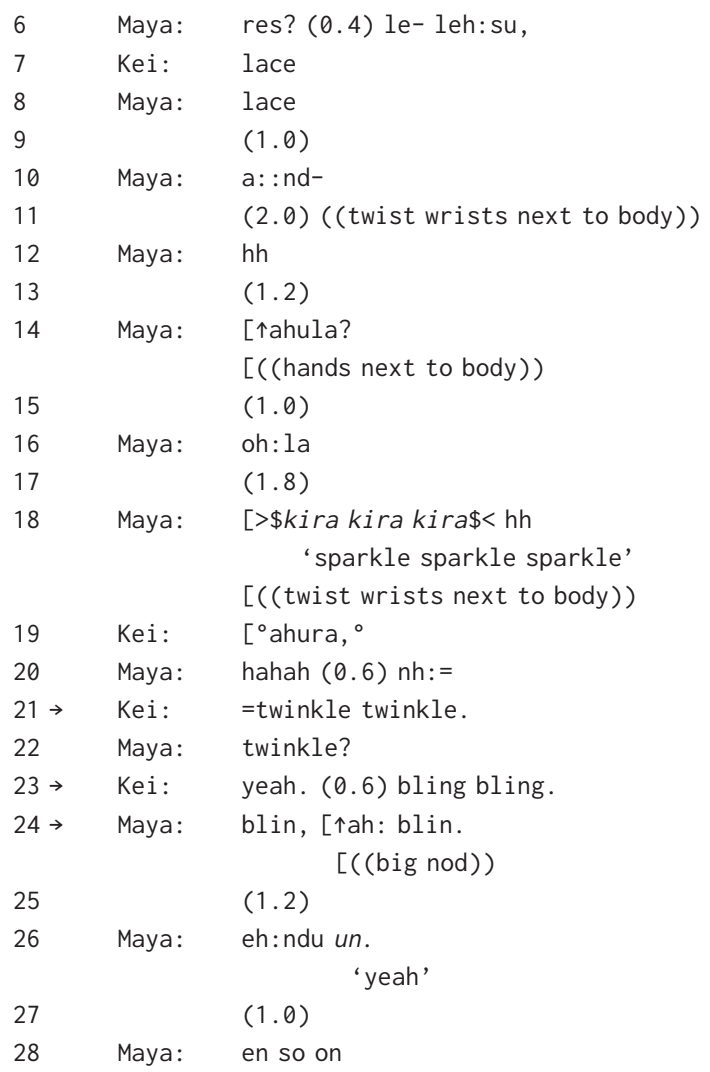

In order to explain the concept of “cute culture", Maya introduces associated images such as "pink" (line 2). After relatively long pauses of 1 and 1.2 seconds (lines 3, 5), she introduces the idea of "lace", however with a Japanese pronunciation, "lehsu" (line 6) with extra vowel sounds. Kei then repairs Maya through introducing a North American pronunciation, "lace" (line 7). Maya repeats this with a similar pronunciation (line 8). This sequence is similar to what Brouwer (2004) calls "doing pronunciation," often found in L1-L2 interactions where the L2 speakers initiates repair with a rising intonation, then the L1 speaker presents their version of the pronunciation, which is then followed by the L2 speaker imitating the pronunciation of the L1 speaker. The similarity of the sequences suggests Kei's positioning of Maya as the novice user of English, and Maya aligning to this positioning.

Kei does not respond to provide confirmation (line 9) and Maya attempts to continue with her explanation (line 10), but pauses again and moves her hands along the side of her body while twisting her wrist, suggesting an on-going solitary word search (Goodwin and Goodwin 1986) (line 11, Figure 1). She then presents her candidate word "ahula" with a rising intonation while looking at 
Kei and using a shorter version of the previous gesture (line 14, Figure 2), which is most likely the Japanese pronunciation of the word "aura." Therefore, the gesture used in lines 11 and 14 can be understood as Maya attempting to describe the atmosphere surrounding one's body (i.e. aura).

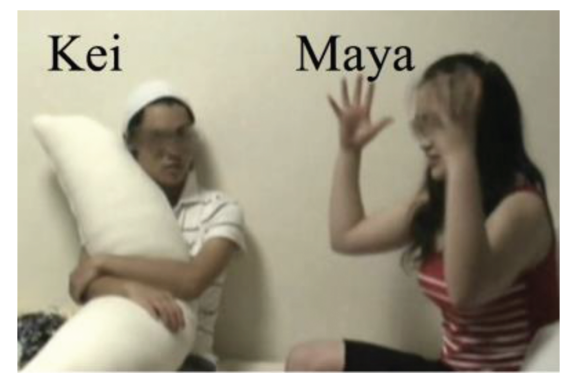

Figure 1: Line 11.

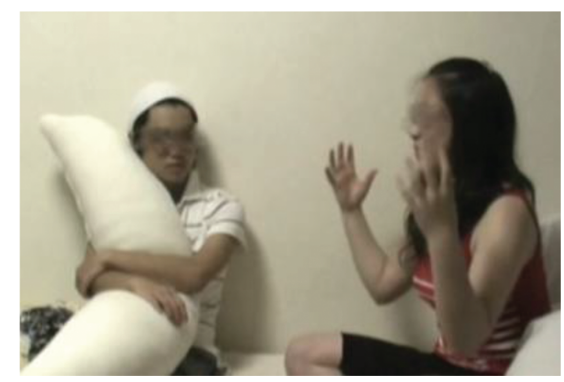

Figure 2: Line 14.

When there is no response from Kei (line 15), she changes the first vowel sound of the word and presents another candidate word "ohla" and waits for a response (line 16). However, Kei again does not respond (line 17). Maya then uses a Japanese onomatopoeia "kira kira kira" ('sparkle sparkle sparkle') possibly to describe the atmosphere that surrounds the cute girls, again with a similar gesture used in line 11 (line 18, Figure 3). Code-switching is a common practice used by L2 speakers to initiate a repair sequence when they cannot find the word for which they are searching (e.g. Mori and Hasegawa 2009). However, Maya's utterance is followed by her laughter (lines 18, 20), thus marking the word and displaying Maya's understanding of "kira kira kira" not being in the desired language for the interaction and will require some interpretive work by Kei (Firth 2009). After repeating what Maya had said, "ahura” (line 19), Kei then repairs Maya by providing a translation in English, "twinkle twinkle” (line 21). Kei’s repair of Maya's turn in line 18 shows that Kei understands some Japanese but orients towards having the interaction conducted in English, as also observed through Maya's laughter in lines 18 and 20. At the same time, Kei shifting the focus to repair Maya's Japanese rather than attempting to resolve the non-understanding of "aura" suggests his interest in possibly progressing the conversation.

When Maya displays non-understanding or uncertainty through a repetition with a rising intonation (line 22), Kei introduces a different expression of "bling bling" (line 23). Maya displays recognition and acceptance of the candidate understanding through "ah" and repetition of the word "bling”. Kei does not explain what "twinkle" or "bling” mean, suggesting that he understood Maya's "ah" and 


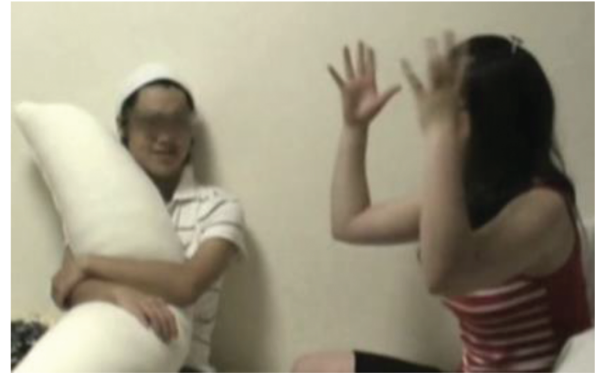

Figure 3: Line 18.

repetition as a confirmation and a sign of mutual understanding. Similarly, Maya does not further pursue the meaning of "twinkle twinkle" or "bling bling", and displays that she has completed her explanation (line 28). Therefore, from a participant-oriented perspective, it can be assumed that the two have reached a mutual understanding of "kira kira kira" as equivalent to "bling bling".

In this excerpt, Kei repairs Maya and provides possible English translations in an attempt to understand the meaning of Maya's utterance (lines 21, 23). Maya then displays agreement to the suggested translation (line 24). The participants in the interaction therefore have agreed on the content, and in theory, have a shared understanding. However, switching to an etic perspective, one would notice that the participants might have slightly different understandings of what is being agreed upon. "Kira kira kira" and "bling bling" hold different connotations and are used to describe different attributes of a person. For instance, a girl who is "kira kira kira" could mean someone wearing cute pink clothes and having curled long hair, while "bling bling" could refer to a person wearing sexy clothes and gaudy jewelry. That said, the hand gesture used by Maya in lines 11, 14 and 18, may have been interpreted by Kei as jiggling bangles. In addition, the protracted repair sequence may have led Maya to accept any sign of Kei's understanding in order to progress the interaction. Nevertheless, this example again shows that even though the interactants indicate that they have reached a mutual understanding as a sequence, it may not be an accurate understanding (i.e. superficial intersubjectivity).

Observing Excerpts (1) and (2), it appears that superficial intersubjectivity arises during repair sequences where there is a difference in the interactional positioning of the speakers in regards to linguistic ability. In Excerpt (1), Hang displays her perception of Ami's novice position through providing a translation of the trouble source in Ami's L1. The translation is then accepted by Ami without question, displaying Ami's alignment to the novice positioning. In Excerpt (2), Kei demonstrates his expert positioning in English and positions Maya as the novice through repairing Maya's pronunciation and providing English translations for a Japanese word. Similar to Ami, Maya aligns to the positioning through repairing 
her pronunciation to sound similar to Kei's, and accepting the translation without question. Furthermore, in both Excerpts (1) and (2), the Japanese participants display their relative novice positions in terms of the English knowledge through requesting for repair to their interlocutors and marking their selected words, or by displaying embarrassment through laughter after the use of Japanese.

Kamio (1994, Kamio 1997) discusses interactants having domains of information (i.e. "territories of information") that are relatively close or distant to them compared to their interlocutor. He describes the knowing and unknowing positions being on a continuum, and argues that this concept can broaden to understand not only who knows, but also who has the right to know the information and the right to express it (Kamio 1997). In the case of ELF interactions, there is an interactional hierarchy or expert-novice positioning in regards to the knowledge of the English language, especially between L1 and L2 speakers (Hosoda 2006; Kurhila 2006), but also between L2 speakers (Kaur 2011a; Siegel 2015). Based on Excerpts (1) and (2), this also seems to be true in international dormitory interactions during repair sequences regarding a word, and the speaker who is positioned as the relative expert seems to hold influence over the repair process.

However, superficial intersubjectivity seems to occur in slightly different interactional contexts as well. Excerpt (3) is between Tomoko, from Japan, and Maria, from the United States, talking about foods they dislike. Tomoko uses the Japanese word "pikurus", a loan word from English for the word 'pickles', which leads to a possible superficial intersubjectivity when Maria identifies it as a trouble source and requests for repair.

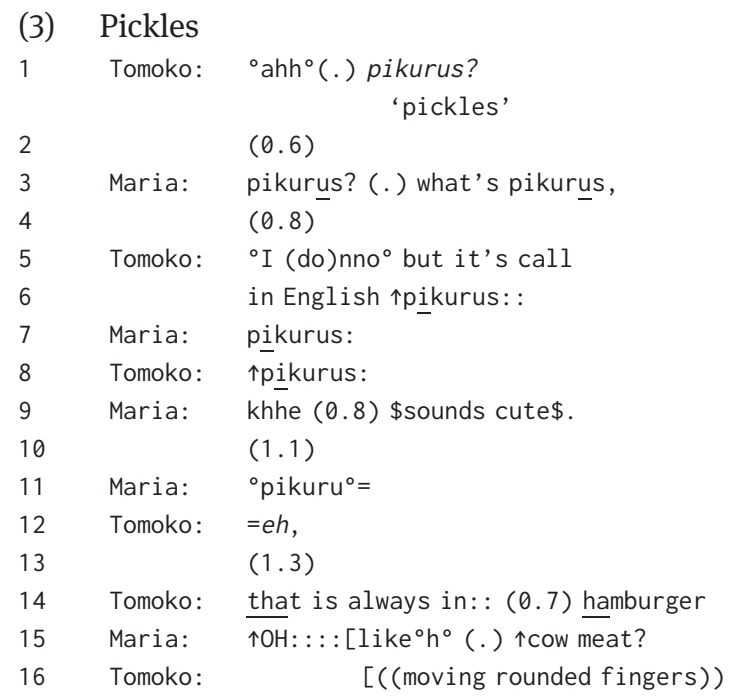




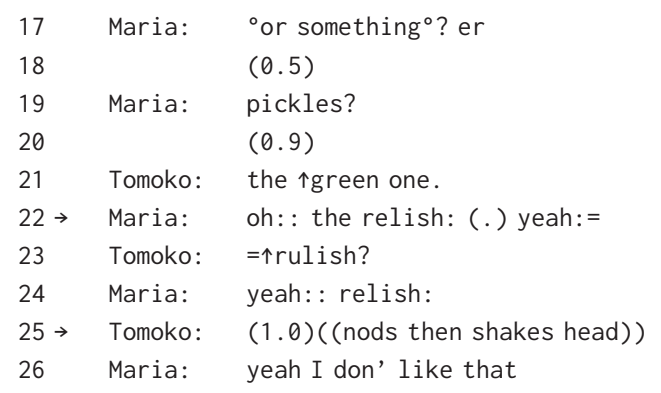

In line 1, Tomoko hesitates and then completes her turn with a candidate word, "pikurus" with a rising intonation. This hesitation could be displaying thinking of the answer to the question rather than searching for a word. However, Tomoko completes her turn with a rising intonation, which also could be understood as a lack of confidence in her word choice and marking it as a potential trouble source (Firth 2009). Maria then explicitly requests repair of the word by asking, "what is pikurus" (line 3). Tomoko does not explain what the object is, but rather, defends her word choice by explaining that it is an English word (lines 5 and 6), despite the fact that Maria is an L1 speaker of English. Here, we can observe that Tomoko, in contrast to Ami or Maya in the previous extracts, seems to position herself as an expert English user.

When the repetition does not solve the non-understanding issue (line 8), Tomoko uses what Goffman (1981) calls a "response cry," "eh" (Hayashi 2009) to initiate a new turn and displays that she is surprised with Maria's response of not knowing the word (line 12). Tomoko then moves on to explain the object (being in a hamburger) and uses a gesture to show the small rounded shape and demonstrates putting the pickle on the hamburger patty (Figure 4). Maria uses "oh" to suggest that she has understood what Tomoko is referring to; however, she then presents her candidate understanding of "cow meat" (line 15) and "pickles" (line 14) with a rising intonation, displaying uncertainty. This is similar to Wong's (2000) finding where participants claim their understanding (e.g. oh, uh-huh), but soon after initiate repair.

Tomoko does not confirm any of the candidate words suggested by Maria (line 20), indicating that they are not the words that describe the object she is referring to. Tomoko continues to provide more hints such as "the green one" (line 21). Maria again shows that she has hit upon an idea ("oh") and presents her candidate understanding of "relish" (line 22). This time, the candidate understanding is presented with no rising intonation and Maria continues her turn to display agreement with Tomoko's dislikes ("yeah") (line 22). Tomoko repeats Maria with a rising intonation with a slightly different pronunciation, which is then confirmed and repaired by 


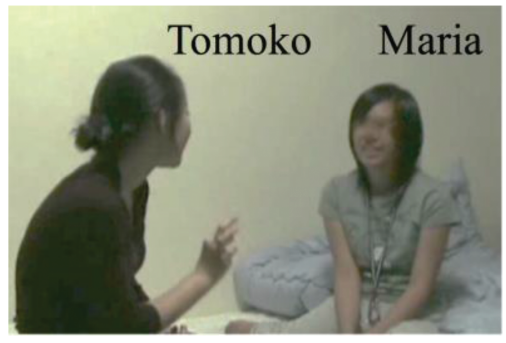

Figure 4: Line 16.

Maria (lines 23 and 24). Unlike Maya in Excerpt (2), Tomoko does not self-repair her pronunciation, but nods and signals the end of the repair sequence, suggesting that she does not position herself as a novice English user in the interaction.

Again, from an emic CA perspective, one can claim that the two participants are using various strategies and affordances, and through cooperative collaboration the two were able to reach a mutual understanding of "pikurus" being "relish". However, switching to an etic researcher perspective, the accuracy of the content is questionable: while "pickles" usually refers to sliced pickled cucumbers or other vegetables, "relish" typically refers to finely chopped pickles mixed with other herbs and spices. Thus, the two have reached a superficial intersubjectivity.

In this case, however, the cause of the superficial intersubjectivity does not seem to be due to the unequal positioning or access to linguistic knowledge. Rather, it seems to be related to Tomoko's claim of English knowledge. In contrast to previous ELF studies and previous excerpts, Tomoko does not seem to demonstrate cooperativeness in achieving an accurate intersubjectivity. Tomoko in line 6 claims her accuracy of her word choice by saying "pikurus" is "English", does not display any uptake of Maria's candidate understanding of "pickles" in line 19, and then does not self-repair her pronunciation or initiate a repair to confirm the meaning of the word "relish" (line 25). Thus, the sequence can be seen as Tomoko avoiding utilizing the sequence as a possible learning opportunity (Brouwer 2003). Despite her inaccurate knowledge of English in this case, Tomoko appears to maintain her position as an expert of the English language, even when speaking with an L1 speaker of English, and prioritizes progressivity over an accurate intersubjectivity. As a result, she displays lack of interest and attention in gaining the accurate word they are searching for, leading to an instance of superficial intersubjectivity.

In the corpus, however, there was a single case where a potential superficial intersubjectivity was avoided. Excerpt (4) is from the same recording as Excerpt (2) between Maya and Kei. They are talking about what Maya learned in her environment class regarding carp, a type of fish. When Maya displays uncertainty with her pronunciation, Kei repairs Maya. However, the two then continue at length to reach an accurate understanding. 
(4) Carp

3

Maya:

the $()>.\uparrow c a: p$ ca: $p<(.)^{\circ} n ?^{\circ}() c a:. p u$ ?

$(0.7)$

Maya: fish (.) $[\mathrm{d}$.

$[(($ fish gesture $))$

Kei: <co: $\underline{\text { d }}>$

Maya: ca-card?

Kei: cod.

(0.6)

Maya: ah: :

$9 \quad(1.2)$

$10 \rightarrow \quad$ Kei: $\quad$ [see oh dee? $((C-0-D))$

11 Maya: [cod

$12 \quad(1.6)$

13 Maya: ma:ybe: :

14 Kei: i->itsa< $\uparrow$ white fish right?

15 Maya: $\uparrow$ white and (.) red.

$16 \quad(0.6)$

17 Kei: >no no.< I mean the meat is (.) white.

18 Maya: white?

19 (1.0)

20 Kei: meat.

21 Maya: meat. [mi- $\uparrow$ meat

22 Kei: [the- the-

23

24

25

26

27

28

29

30

31

32

33

34

35

36

37

$38 \rightarrow$

the <fish's $\uparrow$ meat is white $>$.

(1.2)

Kei : $\quad<\operatorname{cod}>$. $=$

Maya: $\quad \Rightarrow$ I I< haven't eat $(0.6)$ the $(0.4)$

co- co:p?

(1.2)

Maya: $\uparrow$ Japanese sound (.) is.

(1.0)

Maya: $\quad \mathrm{EH}$ ? (0.6) $\mathrm{co}^{-}>\mathrm{AH}<(.) \uparrow C A h:(.) \mathrm{pu}$. (1.0)

Maya: $\quad{ }^{\circ} \mathrm{ca}:$ p. ${ }^{\circ}($.$) fish. (0.8) in Japan$ re- red (.) ca:p. (0.6) or black $\$ c a: p . \$$ (1.4)

Kei : $\quad$ red and black? (0.4)

Maya: [\$plea:se hhh my (h) di(h)ctionary: :\$ . hhh [((Maya reaches out her arms)) 


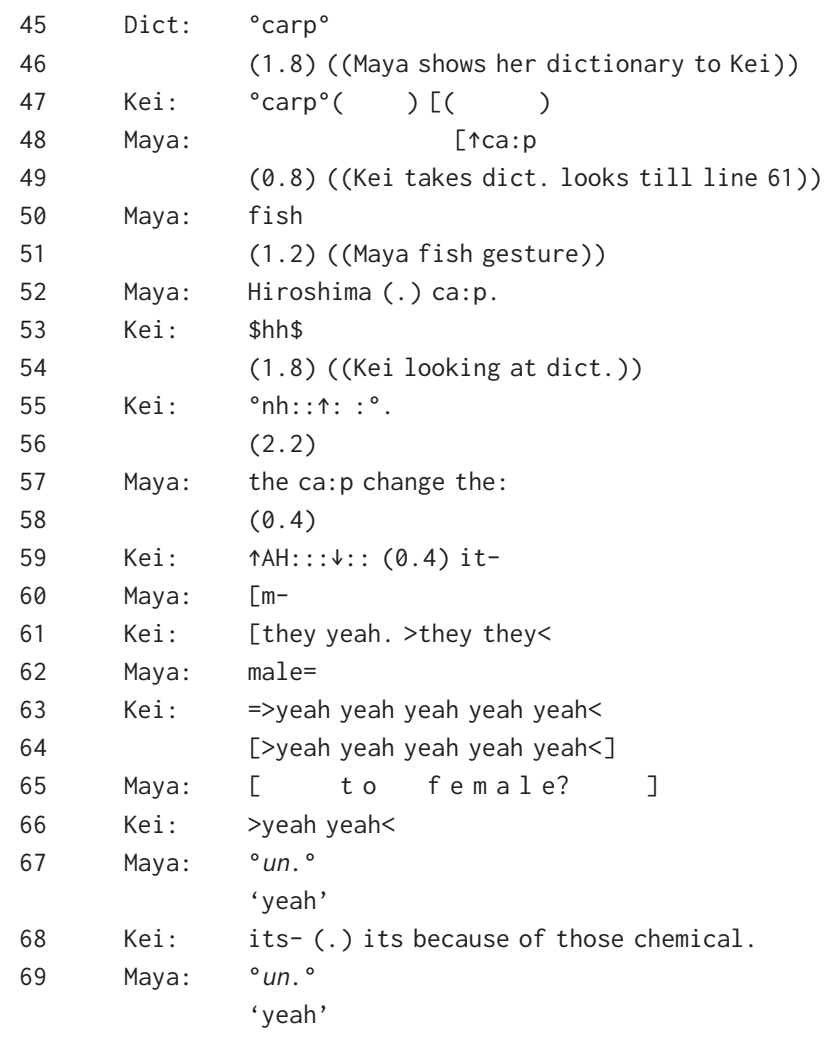

*Dict: Dictionary

In line 1, Maya introduces the topic "carp", but with cut-offs, pauses and hesitation, and a rising intonation displaying a possible ongoing word search and uncertainty of her word choice. Maya provides a word association, "fish" and a gesture in an attempt to gain mutual understanding (line 3, Figure 5). Kei, as his frequent practice, repairs Maya with "cod” (line 4). When Maya does not repeat it in the same manner (line 5), Kei presents his version of the pronunciation again (line 6). Maya does not respond to this second repair immediately and displays thinking through "ah", silence, and repeats "cod" (lines 7-9, 11). It is unclear here if Maya is thinking of the word "cod" or if she is returning to the main topic and thinking of what to say next. However, Kei then presents the spelling "C-O-D" with a rising intonation to prompt a response and to confirm his understanding (line 10).

Although Maya does not provide an immediate or definite response to this question (lines 12 and 13), Kei attempts to resolve the non-understanding through describing the meat color (lines 14, 17, 20). However, again, he fails to do so due to 
Maya describing the color of the outside of the fish (line 15), and then explaining that she has never eaten the fish (lines 26 and 27). Maya then introduces her "Japanese sound" of the word "carp" again (lines 31-33) and then describes the color (line 34).

When these negotiation turns do not work to resolve the non-understanding, Maya then requests her dictionary (line 38). While she is looking up the word, she asks Kei if he knows the Japanese baseball team called "Hiroshima Carp" (lines 40 and 41). This could be interpreted as Maya demonstrating her knowledge and accuracy of the word “carp” using concrete examples. Kei however shakes his head in response, suggesting that he does not know the name of the team (line 42). Maya then plays the audio of the dictionary for "carp" (lines 44 and 45), and then shows the dictionary to Kei (line 46, Figure 6). This pronunciation from the dictionary is then repeated by Kei (line 47) and Maya (line 48). Only when Kei looks at the dictionary closely (lines 49-61, Figure 7) does he display acceptance or understanding through a soft but elongated "nh" (line 55). After Maya notices that Kei has accepted her self-repair and that they have reached a mutual understanding, she continues with her storytelling.

Although Maya questions the candidate word "cod", repeats "carp" several times with varying pronunciations, and provides an example of the baseball team name, Kei does not display understanding. After an extended question and answer sequence, Kei finally displays a change of state when he sees the dictionary entry. This is contrastive with Maya's actions in Excerpt (2) lines 6-8, 23 and 24, where she accepts Kei's repair immediately, thus suggesting Kei’s continuing perception and positioning of Maya as the novice English user in the interaction. In other words, the dictionary was the last method that Maya could resort to in supporting her word choice and having Kei understand the object she was referring to. This non-understanding by Kei could be due to Maya's non-standard pronunciation or Kei's lack of familiarity with fish names. Nevertheless, until Maya demonstrates and supports the accuracy of her candidate word "carp" accompanied with a dictionary, Kei does not display alignment. Thus, similar to Okada's (2015) and Reichert and Liebscher's (2012) findings, the dictionary held a key role in the L2 repair process.

Comparing the four examples of repair sequences regarding a single word analyzed in this study, there seems to be a connection between superficial intersubjectivity, preference towards progressing the conversation, and the speakers' expert-novice positioning in terms of their linguistic knowledge. In Excerpts (1) to (3), the Japanese participants display trouble understanding an English word or producing a "standard" English word that can be understood by their interlocutor. In addition, in Excerpts (1) and (2), the Japanese participants are positioned by their partners as relative novice English speakers through being provided translations in their L1 or having their pronunciation repaired. When they are provided a candidate word by their relative expert interlocutor, they see it as sufficient and progress the interaction. In Excerpt (3), the Japanese participant maintains her expert 


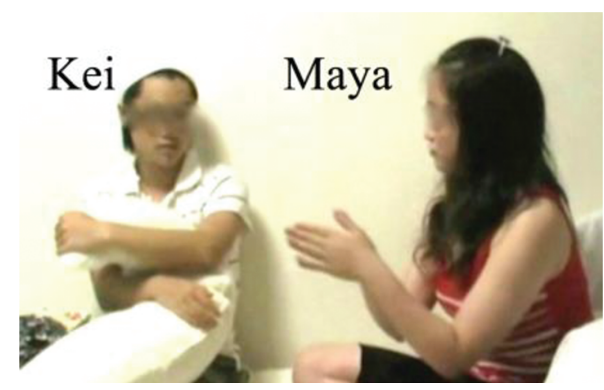

Figure 5: Line 3.

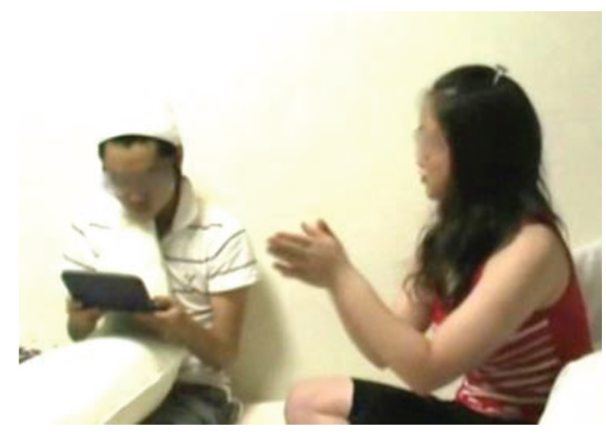

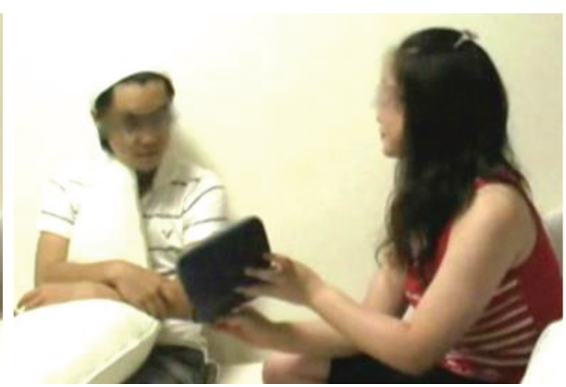

Figure 6: Line 46.

Figure 7: Line 51.

positioning despite her lack of English knowledge, and displays preference towards progressing the conversation. Moreover, the Japanese participants accept the candidate words presented by their partner without question. In contrast, in Excerpt (4), Maya is able to refute Kei's candidate word and convince him of the accuracy of her initial word choice. This was possible because Kei provided the opportunity for negotiation by starting another repair sequence, had a concrete example to support her word choice, and had assistance of the dictionary. However, if she did not have any of these, she may have accepted Kei's candidate understanding of "cod" and progressed the interaction after Excerpt (4) line 8 when she utters "ah", and thus possibly leading to a superficial intersubjectivity.

This does not necessarily mean Kei is not cooperative. Maya and Kei collaboratively used candidate pronunciations, spelling, gestures, and word associations in co-constructing an accurate intersubjectivity. In addition, Kei's action of seeking confirmation in Excerpt (4) line 10 started the relatively long repair sequence and allowed the two to avoid superficial intersubjectivity. When Maya was provided the opportunity after Excerpt (4) line 10, she was able to demonstrate the accuracy of her word choice. This is similar to classroom interactions where students are able to raise questions to the teacher and demonstrate their understanding and non- 
understandings of the content only when provided the opportunity (Wong and Waring 2009). Otherwise, the novice speaker (e.g. students) may lack the opportunity or ability to raise questions, stay silent, and as a result, mis- or non-understandings may stay unnoticed.

\section{Discussion}

In the current study, superficial intersubjectivity occurred in interactional contexts where one of the speakers initiated a repair sequence due to non-understanding of an English word or could not locate the "standard" English word. Then, an inaccurate candidate word was agreed upon through the interaction. The identified phenomenon of superficial intersubjectivity differs from previous studies on miscommunication or misunderstanding (e.g. Weigand 1999; Hinnenkamp 2003). In the case of superficial intersubjectivity, the word has been identified as a trouble source, has been negotiated in the talk, and mutually agreed upon, but still, speakers arrive at an inaccurate understanding. This phenomenon is also different from Firth's (1996) findings of "let it pass" or "make it normal" moves in ELF interaction in that the misunderstanding is not noticed by either party, nor does it become apparent during the interaction. In "let it pass" or "make it normal" moves, at least one of the participants in the talk displays noticing of the gap in their understanding of the others' utterance. In the case of superficial intersubjectivity, the talk moves on without the difference in the speakers' understandings being noticed or raised. Moreover, this phenomenon could be observed due to using CA, an emic participant-oriented perspective, followed by an etic researcher observation.

One interesting observation related to superficial intersubjectivity is that the participants initially begin a repair sequence, which suggests that at least one of the participants considers the information as somewhat important. In addition, the participants display mutual understanding at the end of the repair sequence. However, using an outsider perspective, the observer can notice that the participants are displaying agreement on different objects. What is more, the participants do not necessarily follow up on the accuracy of the information they are provided or agree upon. This suggests that participants are willing to proceed in the conversation, even if some uncertainty exists, demonstrating some tolerance for ambiguity.

It is unclear at a glance why this phenomenon occurs. It could be due to the fact that the participants are talking in a non-critical situation (university dormitory small talk) where there are no foreseeable consequences due to the misunderstanding. During the 22-month longitudinal data collection stage for the present study, these instances of misunderstandings did not show any consequence later in the same recording or in later recording sessions. A plausible 
reason for the cause of superficial intersubjectivity, as discussed through the analysis, is due to the self-and-other positioning or the claim of knowledge of the language in use. Despite the general cooperativeness of the participants in ELF interactions during repair sequences (Firth 1996; Kaur 2011a; Seidlhofer 2001), there still seems to be, even in university dormitory interactions, a hierarchy or a negotiation of expertise among the participants regarding their language use and communication commonly identified in L1-L2 interactions (e.g. Hosoda 2006).

Phillipson notes the inequality in ELF interactions and states, "labelling English as a lingua franca, if this is understood as a culturally neutral medium that puts everyone on an equal footing, is simply false" (Phillipson 2008: 5). Funayama also maintains that in cross-linguistic interactions, "a word search initiated by a nonnative speaker contains, perhaps more clearly, a request-answer dynamic between the less knowledgeable and the more knowledgeable, although this does not eliminate the collaborative, competitive, and negotiable nature of a word-search" (Funayama 2002: 53), and discusses the imbalance of linguistic knowledge manifested in initiation of repair sequences regarding a word. The examples of repair sequences in the present research align with these studies and demonstrate that in ELF interactions, even between L1 and L2 speakers, there is a delicate negotiation of the territory of knowledge of the English language or the specific word the participants are searching for, and not all speakers are positioned equally at all times.

In classroom interactions or in interactional contexts where the participants orient to the interaction as language-learning opportunities, participants in the interaction have been found to consider a candidate word by a peer as insufficient, and would refer to an "authoritative source" such as a dictionary to confirm the accuracy of the word (e.g. Reichert and Liebscher 2012). However, when the participants do not orient to the sequence as a potential language-learning opportunity and they consider their peer's candidate word as sufficient, they do not further pursue the accuracy via an authoritative source. Although the difference in linguistic knowledge is necessary to complete repair sequences regarding a word, when the repair is insufficient, the novice speaker is not able to question the provided candidate word, and an inaccurate mutual understanding is reached. Therefore, the tension and dilemma during repair sequences regarding language knowledge is connected with the phenomenon of superficial intersubjectivity and may well be a unique feature of ELF interactions.

\section{Conclusion}

The current study investigated the phenomenon of superficial intersubjectivity during repair sequences regarding a single word. As previous studies have 
demonstrated, participants take multiple steps to prevent non-understandings and secure intersubjectivity. However, at times, speakers display mutual understanding and continue with the conversation despite agreeing on different objects. The present study is based on a small sample size using an unconventional approach to interactional data; thus, more cases need to be collected and analyzed to make any strong claims. Nevertheless, based on the current analysis, interlocutors' positioning of their language abilities, or the claims of their language abilities, seem to influence the process of achieving intersubjectivity and thus lead to potentially inaccurate understandings of a word and possibly of each other. In contrast to business phone calls, service encounters, or classroom interactions, accuracy of the mutual understanding does not always seem to be prioritized in university dormitory interactions, although provided the opportunity, novice speakers can contribute to achieving an accurate mutual understanding. During repair sequences in ELF interactions where the difference in the speakers' knowledge is utilized in completing the repair, statements made by the speaker with relatively stronger linguistic ability seem to maintain strong influence over the interaction. This interactional environment prompts the interlocutor with relatively weaker ability to agree to inaccurate understandings, and as a result, creates a unique phenomenon of superficial intersubjectivity in ELF interactions.

\section{Appendix: transcription conventions (adapted from Jefferson 2004)}

(.)

$(0.3)(2.6)$

CAPS

$\uparrow$ word, $\downarrow$ word

\$word\$

A: word [word

B: $\quad$ [word

ha ha, huh, heh, hnh

(h), (hh)

.hhh

wo: : :rd

word

A: word=

$\mathrm{B}:=$ word

${ }^{\circ}$ word $^{\circ}$
Short untimed pause

Duration of silence in seconds

Relatively high volume

Pitch rise or fall in the next phrase

Smiley voice

Overlapping talk

Laughter, depending on the sounds produced Laughter within a word

A dot-prefixed row indicates inbreath

Colons show extension of the sound before it

Underscoring indicates some form of stress

Latching speech

Utterance that is quieter than the surrounding talk 


\author{
$>$ word word $<$ \\ $<$ word word $>$ \\ word? \\ word. \\ word, \\ word- \\ $\rightarrow$ \\ (word) \\ ((sobbing))
}

Inward arrows show faster speech, outward slower

Rising intonation

Falling intonation

A slight rise in intonation

An abrupt stop in articulation

Feature of interest to the analyst

Word or parts of a word transcriber is unsure of

Other details of the conversational scene

\section{References}

Archibald, Alasdair, Alessia Cogo \& Jennifer Jenkins. 2011. Latest trends in ELF research. Newcastle upon Tyne: Cambridge Scholars Publishing.

Author. 2015.

Bjørge, Anne Kari. 2012. Expressing Disagreement in ELF Business Negotiations: Theory and Practice. Applied Linguistics 33(4). 406-427.

Björkman, Beyza. 2011. Pragmatic strategies in English as an academic lingua franca: Ways of achieving communicative effectiveness?. Journal of Pragmatics 43(4). 950-964.

Bolden, Galina B. 2012. Across languages and cultures: Brokering problems of understanding in conversational repair. Language in Society 41(1). 97-121.

Borggreen, Gunhild. 2013. Cute and cool in contemporary Japanese visual arts. The Copenhagen Journal of Asian Studies 29(1). 39-60.

Brouwer, Catherine E. 2003. Word searches in NNS-NS interaction: Opportunities for language learning?. The Modern Language Journal 87(4). 534-545.

Brouwer, Catherine E. 2004. Doing pronunciation: A specific type of repair sequence. In Rod Gardner \& Johannes Wagnereds., Second language conversations, 93-113. London: Continuum.

Cogo, Alessia. 2010. Strategic use and perceptions of English as a Lingua Franca. Poznań Studies in Contemporary Linguistics 46. 295-312.

Cogo, Alessia \& Martin Dewey. 2006. Efficiency in ELF Communication: From Pragmatic Motives to Lexico-grammatical Innovation. Nordic Journal of English Studies 5(2). 59-93.

Cogo, Alessia \& Martin Dewey. 2012. Analysing English as a lingua franca: A corpus-driven investigation. London: Continuum.

Drew, Paul. 1995. Conversation analysis. In Jonathan A Smith, Rom Hareé \& Luk Van Langenhoveeds., Rethinking Methods in Psychology, 64-79. London: Sage Publications.

Firth, Alan. 1996. The discursive accomplishment of normality: On 'lingua franca' English and conversation analysis. Journal of Pragmatics 26(2). 237-259.

Firth, Alan. 2009. Doing not being a foreign language learner: English as a lingua franca in the workplace and (some) implications for SLA. International Review of Applied Linguistics in Language Teaching 47(1). 127-156.

Fox, Barbara, Makoto Hayashi \& Robert Jasperson. 1996. Resources and repair: A crosslinguistic study of the syntactic organization of repair. In Elinor Ochs, Emanuel A Schegloff \& Sandra A Thompsoneds., Interaction and grammar, 185-237. Cambridge: Cambridge University Press. 
Funayama, Izumi. 2002. Word-searches in cross-linguistic settings: Teaching-learning collaboration between native and non-native speakers. Crossroads of Language, Interaction, and culture 4. 33-57.

Glenn, Phillip. 2003. Laughter in interaction. Cambridge: Cambridge University Press.

Goffman, Erving. 1981. Forms of talk. Philadelphia: University of Pennsylvania Press.

Goodwin, Marjorie Harness \& Charles Goodwin. 1986. Gesture and coparticipation in the activity of searching for a word. Semiotica 62(1/2). 51-75.

Greer, Tim. 2008. Accomplishing difference in bilingual interaction: Translation as backwardsoriented medium repair. Multilingua-Journal of Cross-Cultural and Interlanguage Communication 27(1-2). 99-127.

Greer, Tim. 2013. Word search sequences in bilingual interaction: Codeswitching and embodied orientation toward shifting participant constellations. Journal of Pragmatics 57. 100-117.

Hayashi, Makoto. 2003. Language and the body as resources for collaborative action: A study of word searches in Japanese conversation. Research on Language and Social Interaction 36 (2). 109-141.

Hayashi, Makoto. 2009. Marking a "noticing of departure": Eh-prefaced turns in Japanese conversation. Journal of Pragmatics 41(10). 2100-2129.

Heritage, John. 1984. Garfinkel and ethnomethodology. Cambridge: Polity Press.

Heritage, John. 2007. Intersubjectivity and progressivity in person (and place) reference. In Tanya Stivers \& N. J. Enfieldeds., Person reference in interaction: Linguistic, cultural and social perspectives, 255-280. Cambridge: Cambridge University Press.

Hinnenkamp, Volker. 2003. Misunderstandings: Interactional structure and strategic resources. In Juliane House, Gabriele Kasper \& Steven Charles Rosseds., Misunderstandings in Social Life: Discourse approaches to problematic talk, 57-81. London; New York: Longman.

Hosoda, Yuri. 2006. Repair and relevance of differential language expertise in second language conversations. Applied Linguistics 27(1). 25-50.

House, Juliane. 1999. Misunderstanding in intercultural communication: Interactions in English as lingua franca and the myth of mutual intelligibility. In Claus Gnutzmanned., Teaching and Learning English as a Global Language: Native and Non-native Perspectives, 73-89. Tübingen: Stauffenburg.

House, Juliane. 2003. English as a lingua franca: A threat to multilingualism?. Journal of Sociolinguistics 7(4). 556-578.

Jefferson, Gail. 1972. Side sequences. In David Sudnowed., Studies in social interaction, 294-338. New York: The Free Press.

Jefferson, Gail. 2004. Glossary of transcript symbols with an introduction. In Gene H Lernered., Conversation analysis: Studies from the first generation, 13-23. Philadelphia: John Benjamins.

Jenkins, Jennifer. 2013. English as a lingua franca in the international university: The politics of academic English language policy. Oxon: Routledge.

Jenks, Christopher Joseph. 2012. Doing Being Reprehensive: Some Interactional Features of English as a Lingua Franca in a Chat Room. Applied Linguistics 33(4). 386-405.

Kamio, Akio. 1994. The theory of territory of information: The case of Japanese. Journal of Pragmatics 21(1). 67-100.

Kamio, Akio. 1997. Territory of information. Amsterdam: John Benjamins.

Kaur, Jagdish. 2009. Pre-empting problems of understanding in English as a lingua franca. In Anna Mauranen \& Elina Rantaeds., English as a lingua franca: Studies and findings, 107-123. Newcastle upon Tyne: Cambridge Scholars Publishing. 
Kaur, Jagdish. 2010. Achieving mutual understanding in world Englishes. World Englishes 29(2). 192-208.

Kaur, Jagdish. 2011a. "Doing being a language expert": The case of the ELF speaker. In Alasdair Archibald, Alessia Cogo \& Jennifer Jenkinseds., Latest Trends in ELF Research, 53-75. Newcastle upon Tyne: Cambridge Scholars Publishing.

Kasper, Gabriele \& Johannes Wagner. 2014. Conversation Analysis in Applied Linguistics. Annual Review of Applied Linguistics 34.171-212.

Kaur, Jagdish. 2011b. Raising explicitness through self-repair in English as a lingua franca. Journal of Pragmatics 43(11). 2704-2715.

Kitzinger, Celia. 2008. Developing feminist conversation analysis: A response to Wowk. Human Studies 31. 179-208.

Kitzinger, Celia. 2013. Repair. In Jack Sidnell \& Tanya Stiverseds., The Handbook of Conversation Analysis, 229-256. Boston: Wiley-Blackwell.

Klimpfinger, Theresa. 2007. "Mind you sometimes you have to mix"-The role of code-switching in English as a lingua franca. Vienna English Working Papers 16(2). 36-61.

Knapp, Karlfried. 2002. The fading out of the non-native speaker. Native speaker dominance in lingua-franca-situations. In Karlfried Knapp \& Christiane Meierkordeds., Lingua franca communication, 217-244. Frankfurt: Peter Lang.

Konakahara, Mayu. 2015. The use of unmitigated disagreement in ELF casual conversation. In Kumiko Murataed., Exploring ELF in Japanese Academic and Business Contexts: Conceptualisation, Research and Pedagogic Implications, 70-89. Oxon: Routledge.

Konakahara, Mayu. 2017. Interactional management of face-threatening acts in casual ELF conversation: An analysis of third-party complaint sequences. Journal of English as a Lingua Franca 6(2). 313-343.

Kurhila, Salla. 2006. Second Language Interaction. Amsterdam; Philadelphia: John Benjamins.

Kuroshima, Satomi. 2010. Another look at the service encounter: Progressivity intersubjectivity and trust in a Japanese sushi restaurant. Journal of Pragmatics 42. 856-869.

Lichtkoppler, Julia. 2007. "Male. Male." - "Male?” - “The sex is male.”: The role of repetition in English as a Lingua Franca conversations. Vienna English Working Papers 16(1). 39-65.

Matsumoto, Yumi. 2011. Successful ELF communications and implications for ELT: Sequential analysis of ELF pronunciation negotiation strategies. The Modern Language Journal 95(1). 97-114.

Mauranen, Anna. 2006. Signaling and preventing misunderstanding in English as lingua franca communication. International Journal of the Sociology of Language 177. 123-150.

Meierkord, Christiane. 2013. Interpreting successful lingua-franca interaction. An analysis of non-native-/non-native small talk conversation in English. Linguistik Online 5(1). https://bop.unibe.ch/linguistik-online/article/view/1013/673. Accessed 3 February 2018

MEXT. 2008. Outline of the Student Exchange System: Study in Japan and Abroad. http://www. mext.go.jp/a_menu/koutou/ryugaku/081210/001.pdf (accessed 5 February 2018).

MEXT. 2011. Project for Establishing University Network for Internationalization - Global 30 -. http://www.mext.go.jp/component/a_menu/education/detail/_icsFiles/afieldfile/2017/ 03/30/1383779_06.pdf (accessed 5 February 2018).

Mori, Junko \& Atsushi Hasegawa. 2009. Doing being a foreign language learner in a classroom: Embodiment of cognitive states as social events. International Review of Applied Linguistics in Language Teaching 47(1). 65-94.

Okada, Yusuke. 2015. Eikaiwa tasuku deno jikokaishi tashashufuku rensa ni okeru gakusei no denshi jisho shiyou [Students' use of electronic dictionaries during self-initiated other repair sequences in English speaking tasks]. Gengo bunka kyoudou kenkyu project 2014. 21-30. 
Phillipson, Robert. 2008. The new linguistic imperial order: English as an EU lingua franca or lingua frankensteinia?. Journal of Irish and Scottish Studies 1(2). 189-203.

Reichert, Tetyana \& Grit Liebscher. 2012. Positioning the Expert: Word Searches, Expertise, and Learning Opportunities in Peer Interaction. The Modern Language Journal 96(4). 599-609.

Rommetveit, Ragnar. 1976. On the architecture of intersubjectivity. In Ragnar Rommetveit \& Rolv Mikkel Blakareds., Studies of language, thought, and verbal communication, 93-107. New York: Academic Press.

Rommetveit, Ragnar. 1985. Language acquisition as increasing linguistic structuring of experience and symbolic behavior control. In James V Wertsched., Culture, communication, and cognition: Vygotskian perspectives, 183-204. New York: Cambridge University Press.

Sacks, Harvey, Emanuel Schegloff \& Gail Jefferson. 1974. A simplest systematics for the organization of turn-taking for conversation. Language 50(4). 696-735.

Schegloff, Emanuel. 1992. Repair after next turn: The last structurally provided defense of intersubjectivity in conversation. American Journal of Sociology 97. 1295-1345.

Schegloff, Emanuel, Gail Jefferson \& Harvey Sacks. 1977. The preference for self-correction in the organization of repair in conversation. Language 53. 361-382.

Schutz, Alfred. 1967. The phenomenology of the social world. Evanston: Northwestern University Press.

Seedhouse, Paul \& Steve Walsh. 2010. Learning a second language through classroom interaction. In Paul Seedhouse, Steve Walsh \& Chris Jenks, Conceptualising 'learning' in applied linguistics, 127-146. Houndmills: Palgrave MacMillan.

Seidlhofer, Barbara. 2001. Closing a conceptual gap: The case for a description of English as a lingua franca. International Journal of Applied Linguistics 11(2). 133-158.

Seo, Mi-Suk \& Irene Koshik. 2010. A conversation analytic study of gestures that engender repair in ESL conversational tutoring. Journal of Pragmatics 42(8). 2219-2239.

Siegel, Aki. 2015. Social epistemics for analyzing longitudinal language learner development. International Journal of Applied Linguistics 25(1). 83-104.

Taguchi, Naoko. 2011. Pragmatic development as a dynamic, complex process: General patterns and case histories. The Modern Language Journal 95(4). 605-627.

Weigand, Edda. 1999. Misunderstanding: The standard case. Journal of Pragmatics 31(6). 763-785.

Wolfartsberger, Anita. 2011. ELF business/business ELF: Form and function in simultaneous speech. In Alasdair Archibald, Alessia Cogo \& Jennifer Jenkinseds., Latest Trends in ELF Research, 163-183. Newcastle upon Tyne: Cambridge Scholars Publishing.

Wong, Jean. 2000. Delayed next turn repair initiation in native/non-native speaker English conversation. Applied Linguistics 21(2). 244-267.

Wong, Jean \& Hansun Zhang Waring. 2009. "Very good" as a teacher response. ELT Journal 63(3). 195-203.

\section{Bionote}

\section{Aki Siegel}

Aki Siegel is a Guest Researcher at Stockholm University, Sweden. She has taught at universities in Japan, Sweden, Vietnam, and the United States. Her research interests include language use and language learning in ELF interactions, conversation analysis, and evidencebased language teaching 